\title{
Scalp Reconstruction Using Integra, an Alternative to Free Tissue Transfer - Case Report
}

\author{
Victoria Fung1, Richard L. Chalmers', Jenny L. C. Geh ${ }^{2}$ \\ ${ }^{1}$ Department of Plastic Surgery, Royal Victoria Infirmary, Newcastle upon Tyne, UK \\ ${ }^{2}$ Department of Plastic Surgery, Guys \& St Thomas' NHS Foundation Trust, London, UK \\ Email: victoria.fung@nuth.nhs.uk
}

Received 5 May 2014; revised 20 June 2014; accepted 30 July 2014

Copyright (C) 2014 by author and OALib.

This work is licensed under the Creative Commons Attribution International License (CC BY).

http://creativecommons.org/licenses/by/4.0/

c) (i) Open Access

\section{Abstract}

We present a case of scalp reconstruction using Integra ${ }^{\circledR}$ and split skin grafting after extensive excision of melanoma in a previously irradiated field. Radical resection of malignancy and application of Integra ${ }^{\circledR}$, a dermal substitute, was performed. Following histological confirmation of complete excision, a split-thickness skin graft (SSG) was applied. After 14 months the patient remains fully healed and without recurrence. The 2-stage use of Integra ${ }^{\circledR}$ and SSG is useful in reconstructing large scalp defects-it produces an acceptable aesthetic outcome and avoids the need for complex free flap surgery.

\section{Keywords}

Irradiated Scalp, Reconstruction, Integra, Resection, Melanoma, Dermal Substitute

Subject Areas: Dermatology, Oncology, Surgery \& Surgical Specialties

\section{Introduction}

The scalp is extremely susceptible to developing skin cancers, associated with prolonged UV sunlight exposure and previous radiotherapy [1]. Surgical excision is the preferred treatment, but can pose reconstructive problems. Resection to bone and adjuvant radiation are often required to minimize risk of recurrence [1] [2].

Recurrence may still occur, necessitating further excision. Soft tissue coverage of post-irradiation calvarium stripped of periosteum is notoriously difficult, often resulting in skin graft failure, infections and chronic wounds. Patients with multiple comorbidities and contraindications to complex reconstructions are left with large areas of bare cranium requiring long-term regular dressings [1]-[3].

We present a case of successful skin healing following recurrent melanoma excision in a scarred and irradi- 
ated scalp, achieved without the need for major free flap reconstruction.

\section{Case Report}

A 69-year-old man presented with new areas of ulceration and nodularity on the scalp. He had a history of nonmelanoma scalp tumours treated by surgical excisions, local flap reconstruction and split skin grafts (SSG). He had received radiotherapy and iodine treatment for scalp ringworm (tinea capitis) at age 6, possible predisposing factors to developing skin cancer [4]. Clinical examination revealed ulcerated and nodular areas, extensive field change with no distinct margins, and scarring from previous surgeries (Figure 1). Punch biopsy showed desmoplastic melanoma of the scalp.

The patient underwent wide excision (2 $\mathrm{cm}$ margins) of the scalp and pericranium under general anaesthesia (Figure 2(a)). An area of $16 \times 16 \mathrm{~cm}^{2}$ was excised. The outer cortex of skull was burred until diploe was visible (Figure 2(b)). Two sheets of Integra ${ }^{\circledR}$ were placed over the defect and secured with staples (Figure 2(c)), and a tieover Urgotulle ${ }^{\circledR}$ and Proflavine wool dressing (Figure 2(d)). The patient received a prophylactic course of oral flucloxacillin, and the tie-over dressings were replaced at weekly intervals for five weeks, without anaesthetic.

Two small areas of haematoma developed beneath the Integra ${ }^{\circledR}$, which required evacuation after week 2. These were allowed to heal by secondary intention.

After 5 weeks, removal of the protective silicon sheet revealed formation of a neodermis (Figure 3). An SSG was harvested from the patient's thigh under local anaesthsia, sutured in place, then dressed with Proflavine wool tie-over. After one week the graft had largely taken. There were focal points of failure at the sites of previous haematoma; these have subsequently healed with hydrocolloid adhesive dressings. There were no problems with infection.

After 14 months the patient remains fully healed with an excellent cosmetic result, no donor site morbidity and no evidence of recurrence (Figure 4).

\section{Discussion}

Extensive scalp malignancies can involve not only the skin but the underlying soft tissues, periosteum and the calvaria through to dura and cerebrum. Tumours with such rapid aggressive progression are treated with radical

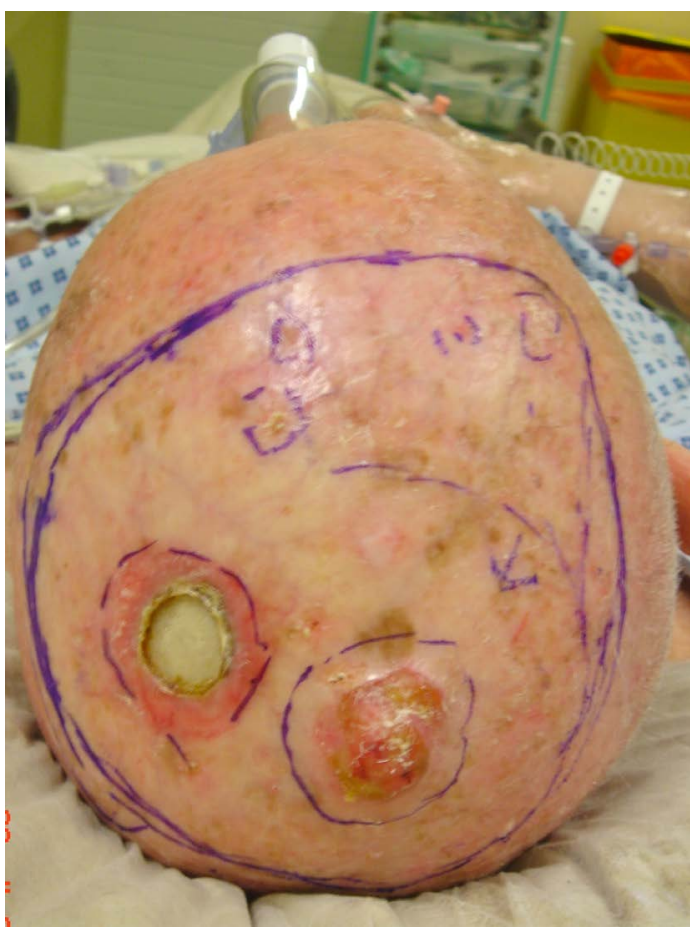

Figure 1. Pre-operative photo showing extensive field change. 


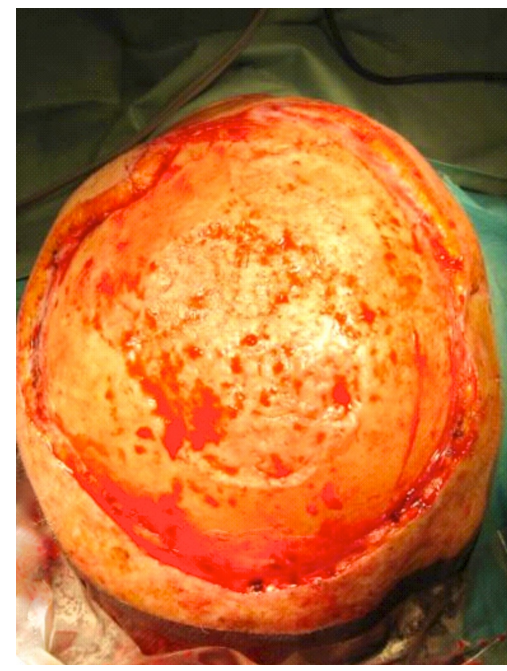

(a)

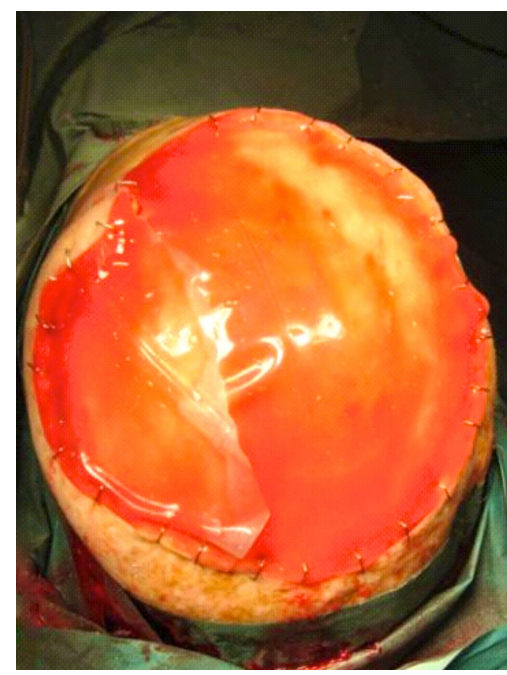

(c)

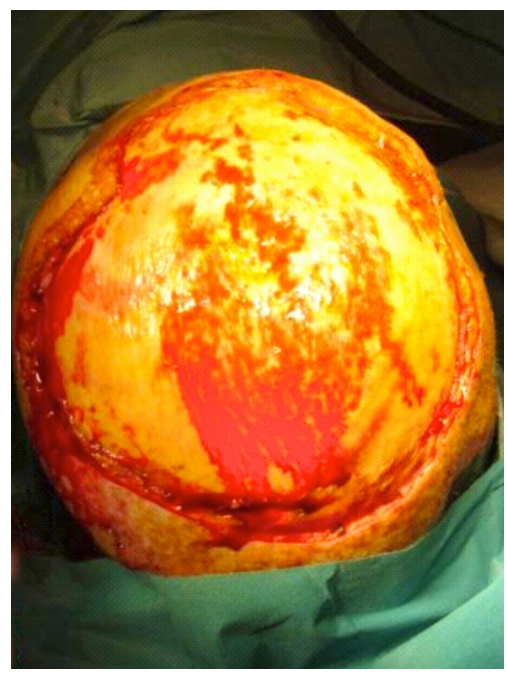

(b)

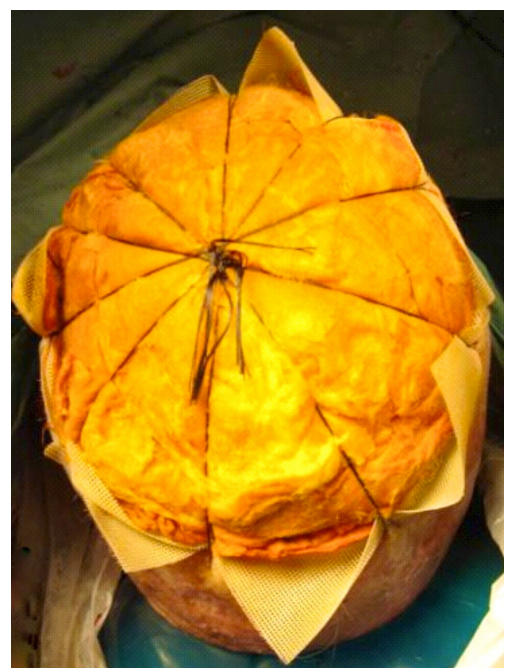

(d)

Figure 2. Intra-operative series: a) Following $2 \mathrm{~cm}$ wide excision including periosteum; then b) burring of the outer calvarial table; c) Following application of Integra $^{\circledR}$, and d) tie-over dressing with Urgotulle ${ }^{\circledR}$ and Proflavine wool.

surgical resection, this remains the gold standard for treatment [1].

The resultant defects pose a complex challenge to the reconstructive surgeon. The success of these operations depends on patient co-morbities and autologous tissue availability. Previous surgery and adjuvant radiotherapy, as in this case, can affect the final result.

Primary closure is problematic in lesions greater than $1 \mathrm{~cm}$ on the scalp. If the periosteum is still intact, an SSG is an option. Local, pedicled or free flaps are desirable for covering large defects. However, the risk of bleeding, length of the procedure, patients' comorbidities and donor site morbidity must be considered [3].

Integra $^{\circledR}$, is a dermal template which allows immediate wound coverage. Its use in managing burns has been well described [5]. However there is little literature on its use for reconstruction following oncological resections [1] [2].

Integra ${ }^{\circledR}$ is bilaminar, the first layer being a sheet of cross-linked bovine collagen and glycosaminoglycans. This matrix is covered by a silicone layer that acts as a temporary epidermis, providing immediate wound closure.

Integra ${ }^{\circledR}$ undergoes three stages of neodermis formation. Initially, the matrix adheres to the wound bed and becomes oedematous. Fibroblasts migrate into the matrix and initiate collagen production. Neovascularisation occurs during weeks 2 - 4, forming a neodermis, which serves as a vascularised bed able to accept an SSG [5]. 


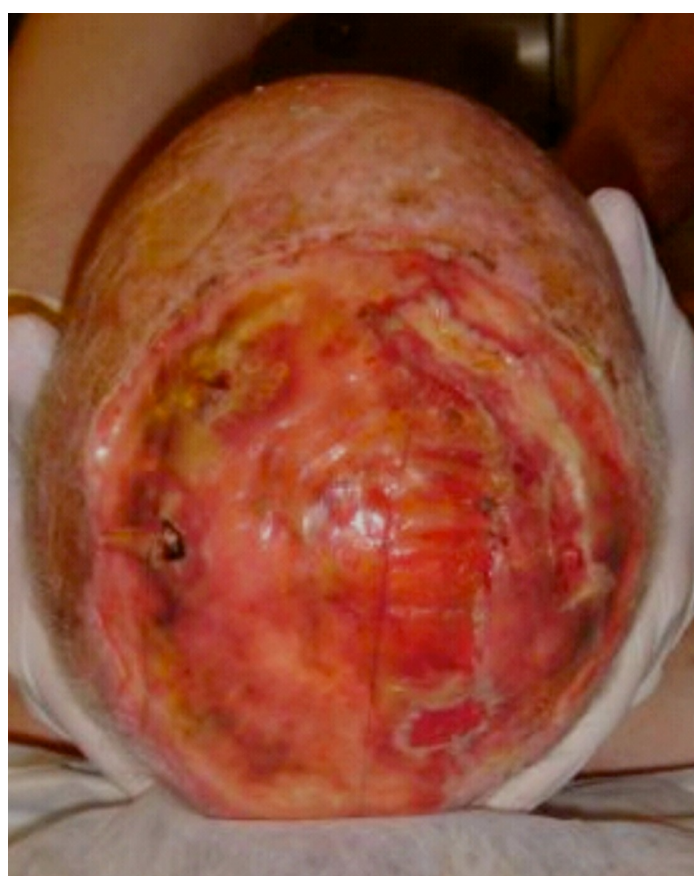

Figure 3. Removal of the outer silicone layer at 5 weeks shows a vascularised bed suitable for grafting.

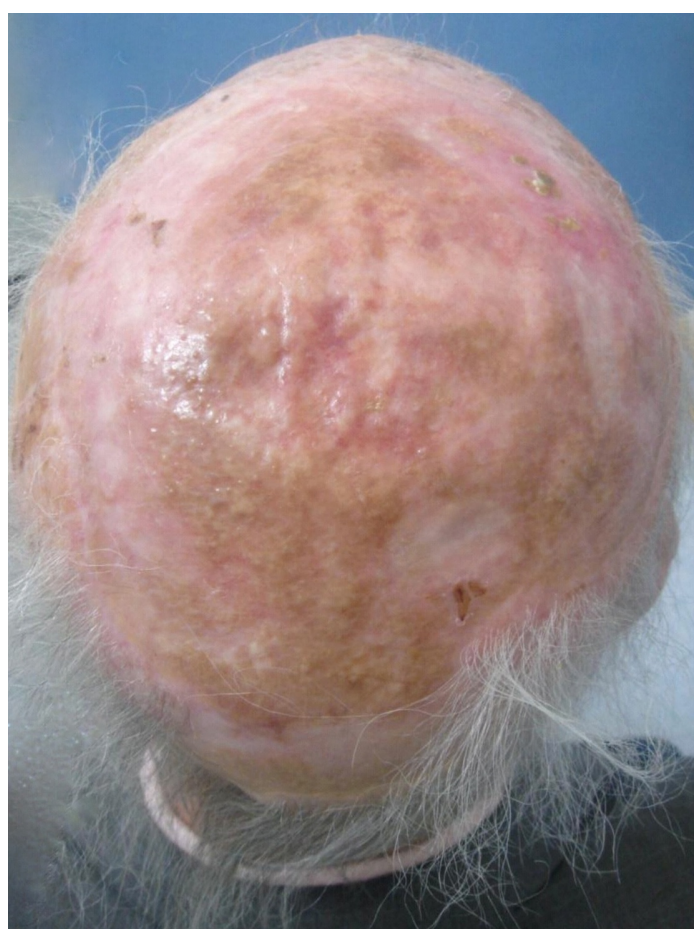

Figure 4. 14 months follow up shows a healthy healed scalp.

One advantage of using Integra ${ }^{\circledR}$ is a good aesthetic outcome due to reduced post-operative contracture and scarring. Integra ${ }^{\circledR}$ allows the use of an SSG, thereby avoiding physiological demands following free flap reconstruction, risk of blood loss, necrosis and donor site morbidity [1]-[3]. Integra ${ }^{\circledR}$ also serves as a biological dressing allowing time for histological confirmation of complete tumour excision. 
A disadvantage is the need for a two stage approach, which is more time-consuming and results in the patient undergoing extra theatre visits, albeit potentially under local anaesthesia. However, operative times are short.

\section{Conclusion}

We have demonstrated successful reconstruction of extensive scalp resection using Integra ${ }^{\circledR}$ and an SSG. Complex reconstructions associated with prolonged hospital stay, donor site morbidity and more significant complications were avoided, the patient returned to normal function after 4 weeks, and showed no signs of recurrence or breakdown at 14-month follow-up. We recommend consideration of this technique when planning extensive scalp resections for malignancy.

\section{Conflict of Interest}

None.

\section{Funding}

None.

\section{References}

[1] Komorowska-Timek, E., Gabriel, A., Bennett, D.C., Miles, D., Garberoglio, C., Cheng, C. and Gupta, S. (2005) Artificial Dermis as an Alternative for Coverage of Complex Scalp Defects Following Excision of Malignant Tumors. Plastic \& Reconstructive Surgery, 115, 1010-1017. http://dx.doi.org/10.1097/01.PRS.0000154210.60284.C6

[2] Gonyon Jr., D.L. and Zenn, M.R. (2003) Simple Approach to the Radiated Scalp Wound Using INTEGRA Skin Substitute. Annals of Plastic Surgery, 50, 315-320. http://dx.doi.org/10.1097/01.SAP.0000046788.45508.A3

[3] Abai, B., Thayer, D. and Glat, P.M. (2004) The Use of a Dermal Regeneration Template (Integra) for Acute Resurfacing and Reconstruction of Defects Created by Excision of Giant Hairy Nevi. Plastic \& Reconstructive Surgery, 114, 162-168. http://dx.doi.org/10.1097/01.PRS.0000129078.41960.92

[4] Sawyer, A.R., McGoldrick, R.B., Mackey, S.P., Powell, B. and Pohl, M. (2007) Malignant Melanoma Following Scalp Irradiation for Tinea Capitis. Journal of Plastic, Reconstructive \& Aesthetic Surgery, 60, 1239-1240. http://dx.doi.org/10.1016/j.bjps.2007.03.014

[5] Moiemen, N.S., Staiano, J.J., Ojeh, N.O., Thway, Y. and Frame, J.D. (2001) Reconstructive Surgery with a Dermal Regeneration Template: Clinical and Histologic Study. Plastic \& Reconstructive Surgery, 108, 93-103. http://dx.doi.org/10.1097/00006534-200107000-00015 